\title{
Seeking to Understand the Impact of Collaboration on Intercultural Communication Apprehension
}

\author{
Laura Jacobi \\ Minnesota State University, United States
}

\begin{abstract}
To assess the impact of collaboration on intercultural communication apprehension (ICA), this mixed methods study compared ICA levels of 41 domestic and international undergraduates who participated in collaborative activities with 79 students in a control group. International student participants came from a variety of countries, while the majority of domestic students were White. A Mann-Whitney U test was used to determine if there were differences in Personal Report of Intercultural Communication Apprehension scores across time between the experimental and control groups. The co-instructors of the collaborative group were also interviewed. Quantitative results indicate no significant differences in ICA levels due to the collaboration. Interview data reveal the potential for collaboration to reduce ICA and for in-group bias and lack of motivation to act as barriers in reducing ICA.
\end{abstract}

Keywords: anxiety management theory, collaboration, intercultural communication apprehension, international students

\section{INTRODUCTION}

Most educators would agree that it is prudent to equip graduating college students with strategies to communicate effectively across cultures, especially considering that these students are entering a globalized workplace and are often nervous about intercultural communication (Campbell, 2016). This is particularly important in light of research suggesting that intercultural communication apprehension (ICA), the anxiety associated with real or anticipated communication with different cultural groups (Neuliep \& McCroskey, 1997, p. 148), impedes cultural understanding and 
adaptation (Chen, 2010; Neuliep, 2012; Shuya, 2007; Swagler \& Ellis, 2003) and is associated with a reduced willingness to communicate (Lin \& Rancer, 2003), ethnocentrism (Toale \& McCroskey, 2001), and perceptions of White racial superiority (Bahk \& Jandt, 2003). For example, Neuliep (2012) found that ethnocentrism and ICA caused individuals to avoid interaction with others from a different culture due to high levels of anxiety. Without interaction, there is no opportunity to reduce uncertainty, and anxiety levels remain high. Therefore, ethnocentrism and ICA act as "superficial causes" that inhibit uncertainty and anxiety management in initial interactions (Gudykunst, 2005, p. 291), which supports Gudykunst's (2005) anxiety and uncertainty management theory (AUM).

A basic premise of AUM is that individuals experience greater uncertainty when communicating with strangers, especially strangers from different cultural groups (Gudykunst, 2005; Gudykunst \& Shapiro, 1996). Subsequent research confirms that those in intercultural situations are likely to feel more anxious than those in intracultural situations (Duronto, et al., 2005; Gudykunst \& Nishida, 2001). Communication in intercultural situations can be stressful and even threatening (Kassing, 1997; Samochowiec \& Florack, 2010); therefore, many domestic students avoid encounters with international students (Campbell, 2016; Neuliep, 2012), even when there is a large international student population on the campus (Leask, 2009; Todd \& Nesdale, 1997; Ward, et al., 2009). Such avoidance is especially problematic for international students for whom sense of belonging is increased (Garcia, et al., 2019) and acculturative stress minimized with connections to the host country and higher levels of social support from host nationals (Sullivan \& Kashubeck-West, 2015). Since domestic students tend to avoid contact with international students and contact is necessary to help all students (domestic and international) to reduce anxiety and gain competence with intercultural communication, the challenge for educators is to find ways to help students reduce their levels of ICA.

Based on their research, Fall et al. (2013) suggested that it is the responsibility of educators to identify techniques to help reduce students' ICA and enhance intercultural competency. Some evidence indicates that exposure to diverse others increases competence, and that the more immersive the exposure, the more effective the communicator (Arasaratnam, 2006; Chen, 2010; Gibson \& Zhong, 2005). Such enhanced competency may be the result of reduced levels of ICA. In other words, as suggested by AUM, exposure to diverse others provides the opportunity to build familiarity and to practice communicating, thereby reducing anxiety levels. Reduced levels of ICA are also associated with increased levels of willingness to communicate (Chen, 2010; Lin \& Rancer, 2003; Neuliep, 2012). Therefore, one potential solution is to provide collaborative opportunities in a safe space between students of different cultures. However, the impact of such collaborative opportunities upon ICA should first be explored empirically.

Universities with large international student populations provide the opportunity to explore the impact of collaboration upon ICA; however, very little research explores the relationship between collaboration and ICA. This is unfortunate considering the results of such studies have the potential to help educators, counselors, and other practitioners to develop interventions that aid international students with better handling acculturative stress and that aid all students with 
initiating and developing cross-cultural relationships. To fill the gap in the literature and compensate for the lack of research that directly explores the potential impact of collaboration on ICA, we developed collaborative classes between a section of domestic students and a section of international students in a basic communication course in a midsized Midwestern university. The purpose of this study was to assess how face-to-face collaborative opportunities affected ICA levels of domestic and international university students. In order to understand whether or not collaborative opportunities will reduce ICA, it is first important to understand what factors contribute to ICA and the larger classification from which it stems, communication apprehension (CA). Studies that examine both CA and ICA are reviewed below.

\section{LITERATURE REVIEW}

\section{Factors Contributing to $\mathrm{CA}$ and ICA}

Two factors stand out in the literature as most significant in contributing to one's level of CA in general and to ICA in particular: one's own culture and one's confidence with the host culture's language.

\section{Culture}

Research reveals that individuals raised in the United States tend to report lower levels of CA than international participants (Croucher, 2013; Hsu, 2004; Mansson \& Myers, 2009; Merkin, 2009; Neuliep, et al., 2003), likely due to the cultural value placed on communication. In individualistic cultures like the United States, where communication is highly valued and encouraged, individuals tend to have lower levels of CA. In contrast, individual expression is less valued in high context cultures - ones that rely upon contextual cues more than direct verbal communication - and members are more apprehensive (Pryor, et al., 2005). The same may be true with levels of ICA. For example, using Neuliep and McCroskey's (1997) Personal Report of Intercultural Communication Apprehension (PRICA), Merkin (2009) found that Koreans were significantly more apprehensive in their intercultural communication $(M=37.21, S D=9.34)$ than Americans $(M=27.79, S D=9.70)$. Merkin concluded the finding was due to Korean focus upon "Confucian values of harmony, not sticking out, and preserving others' face by not taking a stand" (p. 6). Clearly cultures that value direct and frequent interaction may provide greater opportunities for practice with intercultural communication.

The significance of practice with communication was also evident in Croucher et al.'s (2015) study, where results revealed that participants from England scored significantly lower than Finnish and German participants on totalCA, dyadicCA, and meetingCA and lower than German participants on publicCA [measures of McCroskey's (1982) Personal Report of Communication Apprehension (PRCA-24)]. Croucher et al. explained the results by examining the differences in public speaking training across these countries. Public speaking training is prevalent in $\mathrm{K}-12$ education and compulsory in many programs in higher education in England; such training is not prevalent in Finland or Germany. In other words, collaborative 
opportunities to practice communication help to reduce $\mathrm{CA}$ and may help to reduce ICA.

\section{Confidence with the Host Language}

Another factor often referenced in the literature as pertinent to CA and ICA is confidence with the host language. For example, Ying (2002) claimed that confidence with English language skills has been positively associated with the formation of relationships between international students and domestic students in the United States. Bahk and Jandt (2003) reported that English language competence among Korean sojourners and immigrants was negatively correlated with CA toward Americans. Finally, using Bahk and Jandt's (2003) Interracial Communication Anxiety Scale, Bahk (2004) found that communication anxiety toward White Americans was inversely associated with English language competence and traveling in the United States for the Taiwanese group $(F=23.98, p<.001)$. For the Polish group, communication anxiety toward White Americans was inversely associated with English language competence and U.S. media consumption $(F=18.27, p<$ .001). In other studies (e.g., Darwish, 2015; Rivas, et al., 2019), a lack of English proficiency acted as a significant barrier for international students in building personal and professional relationships with host students. To summarize, when foreigners felt confident in their English language skills and had exposure to the American culture, their communication anxiety was lower. These studies revealed the significance of confidence with the host language in reducing ICA. Taking into account cultural differences and the importance of feeling confident in using the language of the host culture, it is possible that opportunities to interact with diverse others in a comfortable environment may help to reduce levels of ICA.

\section{Relationship between CA or ICA and Collaboration}

There are very few studies that examine the relationship between CA and collaboration, and even fewer that examine the relationship between ICA and collaboration. Of the existing literature, some of it explores the impact of CA or ICA on participants' desire to collaborate or interact with diverse others. For example, in a study to test a proposed model of the relationship between ethnocentrism, ICA, intercultural willingness to communicate, and intentions to participate in an intercultural dialogue program, Lin and Rancer (2003) invited 339 college student participants to complete surveys measuring each of the listed concepts. Despite the direct influence of ethnocentrism on individuals' intentions to participate in an intercultural dialogue program, they found that ICA had no direct influence on intentions to participate. However, this was survey research, used to assess students' perceptions as to whether or not they would be interested in participating in a hypothetical intercultural dialogue program; it was not experimental data and therefore did not assess students' actual behavior.

There is also research suggesting that low levels of CA contribute to higher levels of interest in interaction. For example, Dobos (1996) examined effects of students' communication expectations and $\mathrm{CA}$ on the development of student motivation in 
cooperative learning group activities and found that students with higher CA were less active in cooperative learning. Similarly, John and Jay (1991) found that college students with low CA tended to prefer cooperative learning. Finally, $\mathrm{Lu}$ and ChiaFang (2008) found that both Chinese and Americans were significantly more willing to communicate with those from a different culture if they had low levels of ICA. Although scant, the bulk of this literature suggests that low levels of CA and/or ICA contribute to a desire to collaborate, but is it also true that collaborative opportunities can help lower one's CA and/or ICA?

There is evidence to suggest that opportunities to collaborate are likely to reduce students' levels of ICA. For example, using the PRCA-24 to measure CA of 295 American and Indian participants, Pederson, et al.'s (2008) regression results revealed that the more often a person encounters and the more important a person perceives a particular communication situation, the less $\mathrm{CA}$ the person experiences in that situation. In other words, the more often an individual has practice in particular communication situations, the less apprehensive they are in those same situations in the future, indicating the importance of frequent interaction opportunities in reducing CA. However, it is unclear as to whether or not the same would be true with ICA specifically.

Rahmani and Croucher (2017) investigated the relative CA score of Iranian Kurds, a minority group that is underdeveloped and marginalized, and the influence of sex, age, and education on CA. Results indicated that Kurds are relatively less apprehensive than many other cultures; the authors concluded that this was due to frequent social encounters. Rahmani and Croucher also found that individuals with more than a BA degree had significantly lower meetingCA and publicCA. Rahmani and Croucher concluded that "a higher degree of education provides students with more social encounters and at the same time the confidence to communicate with more knowledge and expertise" (p. 9). These results suggest that CA may be reduced with increased opportunities to interact.

Bahk (2004) explored how 289 Taiwanese and Polish college students' real and mediated contact with White Americans was related to their levels of communication anxiety in interaction with them. Bahk found that real contact with White Americans in the United States significantly reduced apprehension for Taiwanese students, and mediated contact reduced apprehension for Polish students, indicating that the intercultural contact helped to reduce CA.

In contrast to these studies, Fall et al.'s (2013) research suggested that intercultural contact alone may not be sufficient to reduce the ICA of students. They assessed the relationship between ICA and emotional intelligence (EI) with 425 students in a public speaking course. Regression results revealed that three of the EI subscales (emotionality, sociability, self-control) predicted ICA such that individuals with higher EI "may be adaptable to avoid the physical and physiological effects of ICA" (Fall et al., 2013, p. 419). In other words, individuals with high EI may be able to mitigate the effects of ICA. With these findings, Fall et al. concluded that "intercultural communication should be approached in the classroom . . through collaboration rather than forced behavioral change" (p. 421). Spencer-Rodgers and McGovern (2002) also found that contact alone with international students did not reduce negative feelings; U.S.-born university students felt "uncomfortable, 
impatient, and frustrated when encountering communication difficulties with the international students on their campuses" (p. 623). Perhaps their discomfort was due to the human tendency toward in-group favoritism. Tajfel's (1974) seminal work on social identity theory suggested that individuals develop an in-group mentality, which prevents them from a desire to connect with others from different cultural backgrounds.

\section{Filling a Gap in the Research}

Despite the conceptual similarities between CA and ICA and the similarities in how they are measured, it is important to recognize that the bulk of the studies reviewed assessed $\mathrm{CA}$ and not ICA. Furthermore, none of the studies directly examined collaborative opportunities between students of different cultures to assess the impact of ICA. In other words, it is still unclear whether or not teacher-structured classroom collaborative opportunities are effective in reducing the ICA levels of students. Therefore, it is imperative that researchers conduct experiments to examine the potential for collaboration to reduce ICA. Such was the aim of this study. Due to the paucity of research directly exploring the impact of collaborative opportunities on ICA levels, and the mixed findings of related studies, the following research question is advanced:

RQ: Will collaborative opportunities in mixed-culture groups reduce the ICA of domestic and international undergraduate students?

\section{METHOD}

\section{Data Collection}

Due to the limited number of participants available for study (i.e., there was only one section of international students, which allowed for collaborative opportunities with one open enrollment section), I recruited student participants through convenience sampling after receiving approval from the Institutional Review Board. Students in six sections of the basic communication course from a mid-sized Midwestern American university were invited to participate. Students in two of those six sections participated in face-to-face mixed-culture collaborations; this included one section of international students and one open enrollment section (with domestic students). Students in the other four sections were enrolled in traditional classrooms (control group). Participants were emailed a link to a Qualtrics survey to be completed anonymously twice during the semester: Week 1 (before collaborative activities) and Week 14 (following collaborative activities). Additionally, I interviewed the two instructors who taught students in the collaborative group to gather their perceptions of the impact of the collaboration upon student ICA levels.

\section{Participant Demographics}

One hundred twenty students participated in the study: 41 in the experimental (collaborative) group and 79 in the control group. About half of the participants in the 
collaborative group $(n=22)$ were international students who came from many different countries, including Colombia, Moldova, China, Nepal, South Korea, India, Saudi Arabia, Ethiopia, Ivory Coast, Nigeria, and the Democratic Republic of Congo. An international student was defined at this university as "a person who is not a citizen or national of the United States and who is in this country on a visa or temporary basis and does not have the right to remain indefinitely." This is reported regardless of racial-ethnic status.

The remaining 19 student participants in the collaborative group were domestic students; of this subgroup, $79 \%$ self-identified as White, $10.5 \%$ Latino, and $10.5 \%$ as other ethnicities. The majority of participants in the collaborative group were aged 18-20 (70.7\%). The remaining participants were aged 21-23 (17.1\%), 24-30 (9.8\%), and $31-40(2.4 \%)$. Most participants were freshmen (41.5\%) or sophomores (43.9\%), while $12.2 \%$ were juniors and $2.4 \%$ were seniors. Finally, $36.6 \%$ of the students in the collaborative group were female.

Seventy-nine students participated as part of the control group. Most participants in the control group self-identified as White $(70.9 \%)$, while the remaining participants identified as other (13.9\%), African American (6.3\%), Latino (5.1\%), or Asian American (3.8\%). The majority of participants in this subgroup were aged 18-20 (89.8\%); the rest of them were 21-23 (7.6\%), 24-30 (1.3\%), or 31-40 (1.3\%). Most of the participants were freshmen $(51.9 \%)$ or sophomores $(40.5 \%)$, with the remainder juniors (5.1\%) and seniors (2.5\%). Finally, $57 \%$ of the participants in this group were female.

Both instructors interviewed were female and in their 20s. One participant selfidentified as African American, and the other White.

\section{Course Structure}

\section{Experimental (Collaborative) Group}

One section of the basic communication course at a mid-sized Midwestern American university was paired with an international student section of the same course for collaborative opportunities in approximately $50 \%$ of the semester classes. The two instructors of the sections co-developed lessons with a focus on intercultural communication and co-taught the collaborative classes. All collaborative activities were a core part of the curriculum and were compulsory; this decision was made due to research that reveals the importance of providing compulsory opportunities for mixed-culture interactions in order for students to feel compelled to participate in them (Borden, 2007; Campbell, 2008, 2012, 2016; Dunne, 2009).

The instructors co-developed lessons with dual purposes: to encourage idea exchange between students and to increase understanding of cultural similarities and differences, as relevant to the course content. In addition, factors that stimulate interaction were taken into account in planning the collaborative activities: nonroutine problems that do not have one right answer (Cohen, 1994), goal and resource interdependence (Johnson, et al., 1990), and rewards for the group while also holding individual group members accountable (Slavin, 1983, 1995). Tasks encouraged interaction and critical thinking. For example, "culture bingo" involved 
students seeking others in the class who were able to sign off on a bingo square due to a match with what was listed on the square. The first student to earn enough signatures for a bingo won the game, but the purpose of the activity was to heighten awareness of cultural similarities and differences. In another lesson, in mixed-culture groups, students were tasked with reflecting upon socialized norms pertinent to group work in their cultures (e.g., structure, roles, and expectations).

Additionally, students were assigned to a mixed-culture group and groups developed final presentations. Some class time was given to work on the presentation, but it was also necessary for groups to meet outside of class time. In an effort to foster relationship development, groups were encouraged to meet in coffee shops or other locations of convenience and comfort to them.

\section{Control Group}

Control group participants were also recruited from sections of the basic communication course. However, they were recruited from sections with a traditional delivery format that did not have collaborative opportunities.

\section{Measurement of Dependent Variable (ICA)}

The data analyzed in this study are part of a larger data set I collected to examine the potential role of collaboration in affecting attitudes relevant to cross-cultural interactions of college students. My goal was to find ways to increase the comfort level of students when engaging in cross-cultural communication in order to increase the potential for all students to learn from the diverse backgrounds of others in a basic communication course. With that goal in mind, I collected data to examine student attitudes and comfort level pertaining to communication with diverse others. In order to fully explicate the quantitative and qualitative findings of the complete data set, they are described in two articles - one on the impact of collaboration upon ethnocentrism, and this one on the impact of collaboration upon ICA. Therefore, in my previous article (Jacobi, 2018), I assessed student responses to an ethnocentrism scale to explore the influence of collaborative opportunities upon ethnocentrism. I found no significant change in the ethnocentric attitudes of students as a result of collaboration. However, it is possible that the anxiety students typically experience in cross-cultural interactions may change as a result of compulsory collaborative opportunities since the comfort and attitudes of students in intercultural interactions may be determined in various ways. Therefore, included in this study are student survey responses to a measure of intercultural communication apprehension (PRICA) and interview responses from the co-teachers of the collaborative group. These dependent measures are described below.

\section{PRICA}

I used the newest version of PRICA (Neuliep \& McCroskey, 1997) to measure the degree of ICA of participants. The PRICA has been used in studies with American, Romanian, Chinese, Korean, and Japanese samples. It has proven to be a 
reliable scale with Cronbach's alpha scores between .90 and .95 (Fall et al., 2013; Gibson \& Zhong; 2005; Lin \& Rancer, 2003; Lu \& Chia-Fang, 2008; Merkin, 2009; Neuliep \& McCroskey, 1997). The Cronbach's alpha was .93 at Time 1 and .92 at Time 2 in this study, again confirming the PRICA as a reliable scale with which to measure ICA. The PRICA includes 14 statements rated on a 5-point Likert scale ranging from strongly disagree to strongly agree. A sample statement is "I am nervous while interacting with people from different cultures." Scores range from 14 to 70, with a high score (i.e., 52 and higher) indicative of a high degree of measured ICA and a low score (i.e., 32 and lower) indicative of a low degree of measured ICA.

I distributed the PRICA to student participants in the collaborative group at two points in the semester to determine whether collaboration would lead to a change in measured ICA: prior to collaborative activities and following collaboration at the end of the semester. I also administered the scale to a control group at the same times in the semester. To test for significant differences in means at Time 1 and Time 2 for both groups, paired samples $t$ tests were used.

\section{Instructor Interviews}

In order to assess the impact of the collaboration upon student ICA from the perspective of the instructors, I interviewed the instructors of the students in the collaborative group separately. Using semistructured interviews, I asked the instructors to share their perception of the benefits and challenges of collaborations between international and domestic students. I also asked them to share their observations of the students during collaborative activities - group dynamics, perceived comfort level in working with diverse others, and changes across the semester in ICA levels.

Interview responses were transcribed and coded by three graduate student assistants. I chose an inductive content analysis for coding due to the paucity of research pertaining to collaboration and ICA, the phenomenon of study. Therefore, following transcription, I trained the graduate student assistants to code using the three stages defined by Elo and Kyngas (2008): open coding, categorization, and abstraction.

During open coding, notes and headings were recorded in the margins while reading through the transcripts. After open coding, lists of categories to be grouped together were created based on the nature of the comments. This allowed similar themes to be grouped into similar, yet broader, categories. Lastly, to engage in abstraction, categories were created using content-characteristic words. For example, interviewees offered themes related to community building, apprehension, and ownership. Results of the coding process are shared in the Results.

\section{RESULTS}

\section{Quantitative Results}

I ran a Mann-Whitney $U$ test to determine if there were differences in PRICA_dif scores between the experimental and control groups. The PRICA_dif scores were 
calculated by subtracting each participant's PRICA Time 1 scores from their PRICA Time 2 scores, which represented the change in PRICA scores over time. This nonparametric test was used because: (a) the sample sizes of experimental group ( $n$ $=41)$ and control group $(n=79)$ were unequal, and (b) the high baseline scores of the majority of participants on the dependent variable at Time 1 (i.e., PRICA 1) suggested the need for a nonparametric test. Distributions for the PRICA_dif scores were not similar, as assessed by visual inspection. PRICA_dif scores for experimental group (mean rank $=60.13$ ) and control group (mean rank $=60.69$ ) were not statistically different, $U=1634.50, z=.083, p=.934$. This suggests that the collaboration did not significantly influence apprehension levels.

\section{Qualitative Results: Instructor Interviews}

\section{Benefits of Collaboration in Reducing ICA}

The instructors claimed three benefits of the collaboration that increased the likelihood of reduced ICA levels: increased opportunity for cross-cultural relationships, potential to challenge assumptions, and desire for collaboration by international students.

One benefit of collaboration is the increased opportunity for cross-cultural relationships. Providing domestic and international students with a platform to interact also provides the potential for relationships to form. The teacher of the domestic students talked about how she enjoyed the opportunity to "intermingle" between two communities - "because you build more bonds." The instructors even talked about their attempts to build relationships with students who were not in their individual sections. For example, the international student instructor claimed that during collaborative lessons, she would intentionally avoid looking at her own students and "would look only at the other instructor's students" in order to engage those students and increase their comfort level with her. Instructors also discussed how they used the collaborative space to build community. The classroom in which they met during collaborative lessons was the same classroom used by the domestic student section during individual lessons. It is a large space with 50 desks, so the instructor of the domestic student section required that her students sit in the first three rows. However, the instructors quickly realized that this was problematic when the international students came for collaborative lessons since they were then relegated to the back three rows and separated from the domestic students. Therefore, the domestic student instructor suggested that her students spread throughout the room. Following the change in seating, domestic students encouraged their group members from the international student section to sit by them, and class engagement and interactions improved.

In addition to increased opportunities to build cross-cultural relationships, the instructors also felt that the collaboration encouraged students to challenge their assumptions. For example, the instructor of the international students discussed the impact of the culture bingo lesson: "The discussion that came up after was kind of something that we couldn't have planned for. It was nice to have students interacting 
with one another, and challenging their assumption of what they think of the world and their globalized view."

Finally, the instructor of the international students noticed a strong desire from her students to collaborate with domestic students. She stated that "a lot of the international students seek those relations with American students . . . but not all American students are willing to give that back to them." Consistent with previous research (e.g., Rivas et al., 2019), it was clear that international students felt motivated to interact with the domestic students and craved the collaborative opportunities; however, that was not necessarily reciprocated by domestic students, which poses a challenge of the collaboration.

\section{Challenges of Collaboration in Reducing ICA}

The instructors claimed three challenges of the collaboration that had the potential to adversely affect ICA levels of students: student apprehension, situational constraints, and instructor ownership.

Despite a strong motivation on the part of international students to partake in the collaboration, there seemed to be apprehension from all students. The instructor of the domestic students said, "I felt like my students were definitely comfortable with each other more so than they were comfortable with the other class." Consistent with previous research (e.g., Darwish, 2015; Rivas et al., 2019), the instructor of the international students recognized lack of confidence with English as the root of apprehension of international students: "They don't feel confident, so I think that that can sometimes trickle down into their group setting." This instructor also perceived the language barrier caused domestic students to be frustrated:

The student from the United States may feel like it's a burden to work with an international student. They may feel like they're not understanding if they're sitting there and just getting head nods, rather than someone actually engaging in the discussion.

The instructor of the domestic students claimed that her students did in fact share their frustration pertaining to the lack of engagement of international students. She put into words how they felt about group interactions with the international students: "No one wants to say anything. So I feel like if I say something they're automatically going to agree and will do it." The apprehension of students, regardless of the cause, certainly has the potential to interfere with their confidence in interacting across cultures.

There were two situational constraints that may have interfered with the effectiveness of the collaborations, resulting in less of an impact on the ICA of students: time limitations and space limitations. The two sections met to participate in collaborative activities eight times over the course of the semester. Although it was expected that the small groups of students also met outside of class to work on their group presentations, both instructors felt that more time together would have been beneficial in reducing apprehension levels. Additionally, the collaborative lessons took place in the classroom used by the domestic student section. An unanticipated 
result of this was that the instructor of the domestic student section felt as if her home space was invaded during collaborative lessons:

It was like, so you're coming into my home and you're engaged with my children. And like something could break ... something could break. So I'm the curator of this museum with all these beautiful glass pieces, and I have a ton of visitors that must engage, but I'm worried.

This same sense of protective ownership was displayed in the interviews of both instructors in regards to their students.

Both instructors were protective of the students in their individual sections. Throughout the interviews, there were consistent references to "my students" and a focus upon what was best for the students in their individual sections as opposed to all students in the collaboration. The instructor of the domestic students admitted to having "become very protective of my students and like, really worried that you know, someone is mistreating them or someone won't do it like I would do it or the way I know I would appreciate it being done." She also claimed that it was difficult to find a balance between "'Yes, you're welcome, please come in, please be involved,' but also like 'I don't appreciate you saying that to my student the way you said it'." This sense of ownership represents a new factor for consideration in studies pertaining to the reduction of ICA.

Student apprehension, situational constraints, and the instructors' ownership over their individual sections may have acted as impediments to effective collaboration and therefore prevented true change in student levels of ICA.

\section{DISCUSSION}

Quantitative findings suggest that collaborative opportunities in mixed-culture groups do not contribute to reduced levels of ICA. However, it is interesting to consider these results in light of the qualitative findings. Qualitative findings indicate that there is potential for collaborative opportunities in mixed-culture groups to reduce the ICA of students. Both instructors recognized the potential for community and relationship building and the likelihood that mixed-culture groups may challenge student-held assumptions. In other words, collaboration provides the opportunity to reduce student ICA, but to be truly effective, collaborative lessons must be designed carefully, taking into account group mentality and motivation.

\section{Group Mentality}

Tajfel's (1974) social identity theory revealed that humans have the tendency toward in-group favoritism. In addition, Sumner (1940) found that people tend to be ethnocentric, perceiving that "one's own group is the center of everything, and all others are scaled and rated with reference to it" (pp. 27-28). Taken together, these suggest that in a classroom setting, students are likely to see things from their own cultural perspective and to be territorial, displaying a sense of protection over those culturally similar to themselves. It is not surprising then that the domestic students and instructor in this study expressed concern when their space was "invaded" by 
another instructor and set of students. It is also not surprising that the co-instructors conveyed a sense of ownership and protection over the students in their individual sections, often referring to them as "my students" and expressing concern over how the co-instructor managed them. This tendency toward territoriality and inclination toward ownership and protection suggests a need to consider ways to mitigate such feelings for collaborations to be successful. Educators might consider a third space for collaborative lessons for example - a space that is not the respective territory of either section for individual lessons. This may help to alleviate any sense that another instructor or group of students is invading a space "owned" by another group, and potentially reduce in-group favoritism and ICA. Educators might also consider immediate implementation of collaboration and more frequent collaborative opportunities. The collaboration in this study did not start until the third week of the semester, after students and instructors had likely already constructed an in-group mentality.

In addition, it would be prudent to focus upon building a shared team culture since research reveals the importance of doing so for successful collaborations (Cramton \& Hinds, 2005; Herrington, 2004; Starke-Meyerring \& Andrews, 2006). For example, Starke-Meyerring and Andrews (2006) implemented a semester-long intercultural virtual team project between a management communication course in the United States and one in Canada. At the end of the semester, they found that some teams never created a successful team culture but "remained firmly fixed on two sides of a fault line," (p. 37) indicating that the mixed-culture groups had formed subgroups along cultural lines, displaying in-group bias for members of their own culture. Herrington (2004) claimed that chaos results when this happens - when students attempt to follow the rules of their own cultures while collaborating with other students from another culture who are doing the same. This is because shared characteristics among only certain group members can create boundaries and divide groups into subgroups (Cramton \& Hinds, 2005). The qualitative data from the instructor interviews in this study reveal some evidence of this. For example, the instructors noted the reticence of students while working in their mixed-culture groups; students appeared hesitant to engage and would often sit in their groups along territorial lines, with domestic students on one side and international students on the other side of the circle. Research reveals that this is problematic because ethnocentric subgroups are less likely to cooperate or share information with the perceived "other" group (Cohen \& Bailey, 1997), which may lead to communication problems and potentially failure (Earley \& Mosakowski, 2000).

\section{Motivation}

In addition to in-group bias, research suggests that motivation is an important consideration for successful collaboration because the more people want to learn about cultural differences, the more likely they will initiate communication with people of a different culture (MacIntyre \& Charos, 1996; MacIntyre et al., 2003). It is possible that the domestic students were less motivated to interact with international students because they did not need to learn about them. They were already in their home culture and likely had a comfortable understanding of the social 
and academic norms. Consistent with previous research (e.g., Kashima \& Loh, 2006; Sakurai et al., 2010; Zhang \& Brunton, 2007), the international students were much more motivated to engage in the collaboration. This is likely because they needed to develop relationships in order to gain an understanding of the host culture and to be successful within it. This fits with previous research suggesting that the location of interaction makes a difference in one's motivation to interact across cultures. For example, Bahk (2004) found that foreigners were far more likely to interact with Americans in the United States than they were if they encountered them in their home countries. This suggests that while international students likely have the motivation to interact and collaborate with domestic students at an American school, the domestic students are much less likely to be motivated and may need additional motivational strategies, such as a direct emphasis on the benefits of working with international students (Campbell, 2016).

Additionally, it is possible that students were not very motivated to interact crossculturally because they started with low levels of ICA. Neuliep and McCroskey (1997) reported that a score below 32 reflects low levels of ICA, and the mean scores at Time 1 were below 32, which likely indicate a lack of motivation to change. According to AUM, individuals who have low levels of anxiety with intercultural communication do not have much motivation to engage cross-culturally because there is no need to reduce their currently low levels of ICA (Gudykunst \& Kim, 1997).

It is also important to consider the fact that the international student instructor recognized a lack of confidence with the English language as an inhibitor for her students. The international students were apprehensive and therefore less motivated to interact during the collaborations because they did not feel confident in their language skills, and this is not surprising considering other research has found the same (e.g., McCroskey et al., 2003; Rivas et al., 2019). Collaborations may be more successful if instructors pair international students with a buddy from the host culture (Campbell, 2012) or find other ways to reassure international students and help them to feel more confident when using the host language.

It seems likely that in-group favoritism and a lack of motivation for cross-cultural interactions both acted as barriers to successful collaboration, preventing true change in ICA levels of students.

\section{CONCLUSION}

\section{Limitations}

There are limitations that should be considered. First, due to the limited number of classes available for study (i.e., one international section of the course available for collaboration), convenience sampling was used, which limits generalizability. In addition, the international student participants came from various cultures. Although many of them shared common experiences and grew up in collectivist cultures, this again limits generalizability. Furthermore, while giving voice to the two instructors involved in the collaboration allowed for an exploration of pedagogical considerations, it is not clear that that the same conclusions would be drawn by other instructors. Finally, despite evidence of the PRICA as a valid and reliable measure of 
ICA, the scale could be insufficient to assess the impact of collaboration upon ICA levels of student participants.

\section{Future Research}

Future researchers might first consider sampling participants with high starting levels of ICA. It is difficult to understand the true impact of collaboration upon ICA levels without the potential for true change to occur. Next, in addition to gathering instructor perspectives, it may be beneficial to gather student perspectives of the impact of mixed-culture collaborations upon ICA through interviews or focus groups. Furthermore, to help prevent the formation of in-group bias, it is important to consider experimental conditions - i.e., a third space for collaborative lessons and immediate and frequent collaborative opportunities; such conditions may increase the likelihood of change in ICA levels. Finally, the motivation of students to engage in mixedculture collaborations should be considered in future studies. Participants in this study may not have been motivated to engage fully, and previous research indicates that motivation may play a role in changing ICA levels of students in mixed-culture collaborations. Future research could explore motivating factors that may contribute to a true change in ICA levels.

Considering the large number of international students in American universities, it is crucial that educators find ways to reduce ICA levels of students, as mitigating ICA increases the potential for successful integration of international students and encourages the development of cross-cultural relationships for all students (international and domestic). Although the quantitative findings of this study indicate that face-to-face mixed-culture collaborations do not affect student levels of ICA, the qualitative findings suggest that there is potential for collaboration to reduce ICA. To create successful classroom collaborations, educators must address the tendency toward in-group favoritism and the potential lack of motivation of domestic students. All of this points to the need for training of instructors prior to implementation of cross-cultural collaborations. For example, if instructors were made aware of the potential for in-group favoritism in advance of the collaboration, they could help to prepare themselves and their students and decrease the potential for the occurrence of such favoritism. They could also take into account the significance of the meeting location for collaborative opportunities and consider the frequency of such opportunities. Finally, future research might examine the utility of motivational strategies in engaging mixed-culture groups in an effort to reduce ICA.

\section{REFERENCES}

Arasaratnam, L. A. (2006). Further testing of a new model of intercultural communication competence. Communication Research Reports, 23, 93-99. doi: $10.1080 / 08824090600668923$

Bahk, C. M. (2004). Perceiving and interacting with white Americans: The role of real and mediated contact among Taiwanese and Polish college students. Journal of Intercultural Communication Research, 33(4), 177-200. 
Bahk, C. M., \& Jandt, F. E. (2003). The perception of Whiteness and interracial communication anxiety among Koreans in the United States. Journal of Intercultural Communication Research, 32(2), 97-115.

Berry, S., \& Woods, R. (2007). Personal report of communication apprehension. In R. A. Reynolds, R. Woods, \& J. D. Baker (Eds.) The handbook of research on electronic surveys and measurements (pp. 364-366). Idea Group Inc.

Borden, A. W. (2007). The impact of service-learning on ethnocentrism in an intercultural communication course. Journal of Experiential Education, 30(1), 171-183.

Campbell, N. (2008). You've got mail! Using email technology to enhance intercultural communication learning. Journal of Intercultural Communication, $16,1-17$.

Campbell, N. (2012). Promoting intercultural contact on campus: A project to connect and engage international and host students. Journal of Studies in International Education, 16(3), 205-227. doi:10.1177/1028315311403936

Campbell, N. (2016). Ethnocentrism and intercultural willingness to communicate. Journal of Intercultural Communication, 40(1), 1.

Chen, G. M. (2010). The impact of intercultural sensitivity on ethnocentrism and intercultural communication apprehension. Intercultural Communication Studies, 19, 1-9.

Cohen, E. G. (1994). Restructuring the classroom: Conditions for productive small groups. Review of Educational Research, 64(1), 1-35.

Cohen, S. G., \& Bailey, D. E. (1997). What makes teams work: Group effectiveness research from the shop floor to the executive suite. Journal of Management, 23, 239-290.

Cramton, C. D., \& Hinds, P. (2005). Subgroup dynamics in internationally distributed teams: Ethnocentrism or cross-national thinking? In B. M. Staw \& R. M. Kramer (Eds.), Research in organizational behavior (Vol. 26, pp. 231-263). JAI.

Croucher, S. M. (2013). Communication apprehension, self-perceived communication competence, and willingness to communicate: A French analysis. Journal of International and Intercultural Communication, 6, 298-316.

Croucher, S. M., Sommier, M., Rahmani, D., \& Appenrodt, J. (2015). A cross-cultural analysis of communication apprehension: A comparison of three European nations. Journal of Intercultural Communication, 2015, 38.

Darwish, R. H. (2015). Sense of belonging among international students enrolled in graduate-level business programs: A case study [Unpublished master's thesis]. Bowling Green State University, $\mathrm{OH}$.

Dobos, J. A. (1996). Collaborative learning: Effects of student expectations and communication apprehension on student motivation. Communication Education, 45(2), 118-134.

Dunne, C. (2009). Host students' perspectives of intercultural contact in an Irish university. Journal of Studies in International Education, 13(2), 222-239. doi:10/1177/1028315308329787

Duronto, P. M., Nishida, T., \& Nakayama, S. (2005). Uncertainty, anxiety, and avoidance in communication with strangers. International Journal of Intercultural Relations, 29, 549-560. doi:10/1016/j.ijintrel.2005.08.003 
Earley, P. C., \& Mosakowski, M. L. (2000). Creating hybrid team cultures: An empirical test of transnational team functioning. Academy of Management Journal, 43(1), 26-49.

Elo, S., \& Kyngas, H. (2008). The qualitative content analysis process. Journal of Advanced Nursing, 62(1), 107-115.

Fall, L. T., Kelly, S., MacDonald, P., Primm, C., \& Holmes, W. (2013). Intercultural communication apprehension and emotional intelligence in higher education: Preparing business students for career success. Business Communication Quarterly, 76(4), 412-426.

Garcia, H. A., Garza, T., \& Yeaton-Hromada, K. (2019). Do we belong? A conceptual model for international students' sense of belonging in community colleges. Journal of International Students, 9(2), 460-487.

Gibson, D., \& Zhong, M. (2005). Intercultural communication competence in the healthcare context. International Journal of Intercultural Relations, 29, 621634.

Gudykunst, W. B. (2005). An anxiety/uncertainty management (AUM) theory of effective communication: Making the mesh of the net finer. In W. B. Gudykunst (Ed.), Theorizing about intercultural communication (pp. 281-322). SAGE.

Gudykunst, W. B., \& Kim, Y. Y. (1997). Communicating with strangers: An approach to intercultural communication. McGraw Hill.

Gudykunst, W. B., \& Nishida, T. (2001). Anxiety, uncertainty, and perceived effectiveness of communication across relationships and cultures. International Journal of Intercultural Relations, 25, 55-71.

Gudykunst, W. B., \& Shapiro, R. (1996). Communication in everyday interpersonal and intergroup encounters. International Journal of Intercultural Relations, 20, $19-45$.

Herrington, T. (2004). Where in the world is the Global Classroom Project? In J. DiLeo \& W. Jacobs (Eds.), If classrooms matter: Progressive visions of educational environments (pp. 197-210). Routledge.

Hsu, C. F. (2004). Sources of difference in communication apprehension between Taiwanese and Americans. Communication Quarterly, 52, 370-389.

Jacobi, L. (2018). Ethnocentric attitudes of American and international students: Assessing the impact of collaboration. Journal of Intercultural Communication Research, 47(6), doi:10.1080/17475759.2018.1506352

John, B., \& Jay, S. (1991). Communication apprehension and learning styles [Paper presentation]. Annual Meeting of the Central States Communication Association, Chicago, IL

Johnson, D., Johnson, R., \& Stanne, M. (1990). Impact of goal and resource interdependence on problem-solving success. Journal of Social Psychology, 129, 507-516.

Kashima, E. S., \& Loh, E. (2006). International students' acculturation: Effects of international, conational, and local ties and need for closure. International Journal of Intercultural Relations, 30, 471-485. doi:10.1016/j.ijintrel.2005.12.003 
Kassing, J. W. (1997). Development of the intercultural willingness to communicate scale. Communication Research Reports, 14(4), 399-407. doi:10/1080/088240997009388683

Leask, B. (2009). Using formal and informal curricula to improve interactions between home and international students. Journal of Studies in International Education, 13(2), 205-221.

Lin, Y., \& Rancer, A. S. (2003). Ethnocentrism, intercultural communication apprehension, intercultural willingness-to-communicate, and intentions to participate in an intercultural dialogue program: Testing a proposed model. Communication Research Reports, 20(1), 62-72.

Lu, Y., \& Chia-Fang, H. (2008). Willingness to communicate in intercultural interactions between Chinese and Americans. Journal of Intercultural Communication Research, 37(2), 75-88.

MacIntyre, P. D., Baker, S. C., Clement, R., \& Donavan, L. A. (2003). Talking in order to learn: Willingness to communicate and intensive language programs. Canadian Modern Language Review, 59, 589-607.

MacIntyre, P. D., \& Charos, C. (1996). Personality attitude and affect as predictors of second language communication. Journal of Language and Social Psychology, 15, 3-26.

Mansson, D. H., \& Myers, S. A. (2009). A reexamination of Swedish and American college students' communicative attributes. Journal of Intercultural Communication Research, 4, 78-96.

McCroskey, J. C., Burroughs, N. F., \& Marie, V. (2003). Relationship of selfperceived communication competence and communication apprehension with willingness to communicate: A comparison with first and second language in Macronesia. Communication Research Reports, 20, 230-239.

Merkin, R. S. (2009). Cross-cultural communication patterns - Korean and American communication. Journal of Intercultural Communication, 20. https://immi.se/intercultural/nr20/merkin.htm

Neuliep, J. W. (2012). The relationship among intercultural communication apprehension, ethnocentrism, uncertainty reduction, and communication satisfaction during initial intercultural interaction: An extension of anxiety and uncertainty management (AUM) theory. Journal of Intercultural Communication Research, 41(1), 1-16.

Neuliep, J. W., Chadouir, M., \& McCroskey, J. C. (2003). A cross-cultural test of the association between temperament and communication apprehension. Communication Research Reports, 20, 320-330.

Neuliep, J. W., \& McCroskey, J. C. (1997). The development of intercultural and interethnic communication apprehension scales. Communication Research Reports, 14, 145-156.

Pederson, J., Tkachuk, H., \& Allen, M. (2008). How perceived situational frequency and situational importance affect communication apprehension: A cross cultural analysis. Journal of Intercultural Communication Research, 37(3), 189-198.

Pryor, B., Butler, J., Boehringer, K. (2005). Communication apprehension and cultural context: A comparison of communication apprehension in Japanese and American students. North American Journal of Psychology, 7, 247-252. 
Rahmani, D., \& Croucher, S. M. (2017). Minority groups and communication apprehension. Journal of Intercultural Communication, 43, 1. Retrieved from: https://immi.se/intercultural/nr43/rahmani.html

Rivas, J., Hale, K., \& Burke, M. G. (2019). Seeking a sense of belonging: Social and cultural integration of international students with American college students. Journal of International Students, 9(2), 687-704.

Sakurai, T., McCall-Wolf, F., \& Kashima, E. S. (2010). Building intercultural links: The impact of a multicultural intervention programme on social ties of international students in Australia. International Journal of Intercultural Relations, 34, 176-185. doi:10.1016/j.ijintrel.2009.11.002

Samochowiec, J., \& Florack, A. (2010). Intercultural contact under uncertainty: The impact of predictability and anxiety on the willingness to interact with a member from an unknown cultural group. International Journal of Intercultural Relations, 34(5), 507-515. doi: 10.1016/j.ijintrel.2010.05.003

Shuya, P. (2007, November). Intercultural communication apprehension, ethnocentrism and their relationship with gender: A cross-cultural comparison between the U.S. and China [Paper presentation]. 93 ${ }^{\text {rd }}$ Annual Meeting of the National Communication Association, Chicago, IL.

Slavin, R. E. (1983). When does cooperative learning increase student achievement? Psychological Bulletin, 94(3), 429-445.

Slavin, R. E. (1995). Cooperative learning: Theory, research, and practice. Prentice Hall.

Spencer-Rodgers, J., \& McGovern, T. (2002). Attitudes toward the culturally different: The role of intercultural communication barriers, affective responses, consensual stereotypes, and perceived threat. International Journal of Intercultural Relations, 26, 609-631. doi:10.1016/S0147-1767(02)00038-x

Starke-Meyerring, D, \& Andrews, D. (2006). Building a shared virtual learning culture: An international classroom partnership. Business Communication Quarterly, 69(1), 25-49.

Sullivan, C., \& Kashubeck-West, S. (2015). The interplay of international students' acculturative stress, social support, and acculturation modes. Journal of International Students, 5(1), 1-11.

Sumner, W. G. (1940). Folkways: A study of the sociological importance of usages, manners, customs, mores, and morals. The New American Library.

Swagler, M. A., \& Ellis, M. V. (2003). Crossing the distance: Adjustment of Taiwanese graduate students in the United States. Journal of Counseling Psychology, 50(4), 420-437.

Tajfel, H. (1974). Social identity and intergroup behavior. Social Science Information, 13(2), 65-93. doi:10.1177/053901847401300204

Toale, M. C., \& McCroskey, J. C. (2001). Ethnocentrism and trait communication apprehension as predictors of interethnic communication apprehension and use of relational maintenance strategies in interethnic communication. Communication Quarterly, 49, 70-83.

Todd, P., \& Nesdale, D. (1997). Promoting intercultural contact between Australian and international university students. Journal of Higher Education Policy and Management, 19(1), 61-75. 
Ward, C., Masgoret, A., \& Gezentsvey, M. (2009). Investigating attitudes toward international students: Program and policy implications for social integration and international education. Social Issues and Policy Review, 3(1), 79-102.

Ying, Y. W. (2002). Formation of cross-cultural relationships of Taiwanese international students in the United States. Journal of Community Psychology, $30(1), 45-55$.

Zhang, Z., \& Brunton, M. (2007). Differences in living and learning: Chinese international students in New Zealand. Journal of Studies in International Education, 11(2), 124-140. doi:10.1177/1028315320628934

LAURA JACOBI, $\mathrm{PhD}$, is an Associate Professor in the Communication Studies Department at Minnesota State University, Mankato. Her major research interests lie in the areas of intercultural communication and communication pedagogy. Email: laura.jacobi@mnsu.edu 